Cronfa - Swansea University Open Access Repository

This is an author produced version of a paper published in:

SPIEL

Cronfa URL for this paper:

http://cronfa.swan.ac.uk/Record/cronfa35425

\title{
Paper:
}

Matthews, G. (2017). Evolving narratives of the First World War in Welsh-language television programmes. SPIEL, 2 (2)

This item is brought to you by Swansea University. Any person downloading material is agreeing to abide by the terms of the repository licence. Copies of full text items may be used or reproduced in any format or medium, without prior permission for personal research or study, educational or non-commercial purposes only. The copyright for any work remains with the original author unless otherwise specified. The full-text must not be sold in any format or medium without the formal permission of the copyright holder.

Permission for multiple reproductions should be obtained from the original author.

Authors are personally responsible for adhering to copyright and publisher restrictions when uploading content to the repository. 


\section{Evolving narratives of the First World War in Welsh-language television programmes}

This article will examine Welsh television programmes about the First World War, particularly those broadcast since 2004 in the Welsh language. There have been many hours of programmes commissioned to benefit from the increased popular interest in the story of the war, particularly at the times of the ninetieth anniversary and the centenary. Whereas programmes produced prior to this period put eyewitness testimony centre-stage, the passing of the last veterans has meant that there has been a shift in the way these programmes are constructed.

It is acknowledged that the presentation of the First World War to a Welsh audience is governed by the general 'British' framework of understandings: clearly everyone who speaks Welsh has access to a wealth of English-language media about the war. Many of the tropes within Welsh-language representations of the war have their direct parallels in English-language culture, yet there are also particular ways of interpreting the war that are unique to Wales.

One particular change that has been seen over the past fifteen years is a shift towards the use of contemporary evidence from the 1914-18 period. This has often led to a presentation of the history that is both broader in scope (as it does not rely on the stories of a few surviving individuals) and deeper in its analysis (in the cases where a voluminous cache of evidence allows a closer examination of the soldiers' experiences). In visual terms, the disappearance of the veterans from the screen has led to a greater reliance on dramatic re-creations and more space for on-screen presenters.

The balance between the 'national' story of Wales' involvement in the war and the wider 'British' or international perspective has also undergone a subtle shift over the years. No longer is the war presented solely in terms of the mud of France and Flanders, but the global aspect of the fighting, and of Welsh involvement in theatres on three continents, is considered. In this context, one particularly interesting example was a two-part series about Gallipoli, co-produced with partners in Australia, New Zealand, Turkey and Ireland, and therefore imbued with a multi-national perspective.

Another focus that has been reinforced by the programmes over the period of the centenary has been the emphasis upon the individual story, examining the impact of the war on a local and familial level. Although these programmes often incorporate familiar narratives (such as ideas regarding the futility of the conflict), by providing a deeper insight into one individual's story, or the common experience of a group of individuals, they can prompt the viewers to consider the wider ramifications of the war upon families, local communities and, by extension, upon the Welsh nation.

Thus as a whole these programmes represent a shift from a narrow focus on the military history of 1914-18 to a broader consideration of the long-term impact of the war upon society and culture in Wales. 


\section{Wales and the First World War}

Of course, Wales is not culturally independent any more than it is economically or politically independent, and any consideration of how the First World War is understood in Wales has to acknowledge and consider the fact that the country is a component part of the United Kingdom, and a minor component at that. In terms of population figures (using the 2011 Census), the Welsh form $4.9 \%$ of the population of the UK, a figure dwarfed by the $83.9 \%$ that come from England. Thus any 'Welsh' interpretation of the First World War (or any other aspect of history) is strongly influenced by the predominant 'British' interpretation. For the British public, the war is "simultaneously fascinating and repellent", an open wound that has never fully healed and that public attention insists upon returning to, picking at the scab (Bond, 1991, p.1). The British narrative is dominated by images of mud and death in France and Flanders: "we think of the war as being distinctively horrendous, marked out from other conflicts for its participants and for us by its particularly awful nature" (Todman, 2005, p.1). This statement is true also of the Welsh retelling of the war, yet there are differences in emphasis, and some features to the Welsh narrative that are distinct and different to that which comes out of England.

As with the majority of European nations, the First World War was a time of great tragedy in Wales, for families, communities and for the whole nation, and a period when rapid change swept away a whole range of certainties and familiar ideas. In a variety of different ways - cultural, political, and economic - it makes sense to talk about Wales 'before 1914' and 'after 1918'. The post-war collapse of Wales' staple industries made the Depression years particularly traumatic for Wales, which means that with hindsight it is difficult to argue that the whole war was anything but futile. The loss of so many young lives (the figure usually given in television documentaries is 40,000$)$ gained nothing but heartbreak for the Welsh.

Thus the popular representation of the war in Welsh culture echoes the British preoccupation for focussing upon the bloody futility of the fighting on the Western Front, for which the blame is laid at the door of the officer class, who are seen as stubborn, stupid and uncaring. Within the Welsh-language context this officer class is further removed from the Welsh soldiers as they were not only belonged to a different social group to the working-class privates, but they (literally) spoke a different language and had a different national loyalty, English rather than Welsh.

One particular story that is extraordinarily prevalent in Welsh-language retellings of the war is that of the talented young poet Ellis Humphrey Evans, known under his bardic name of Hedd Wyn. Every Welsh-speaker knows the story of how he was named as the winner of the most prestigious poetry prize at the National Eisteddfod in 1917, only for the announcement to be made that he had been killed in action seven weeks earlier (Morris, 2012). Other narratives that are familiar to a Welsh audience are those that emphasise the roles of Welsh units, in particular the Battle of Mametz Wood (9-12 July 1916). In terms of individual contributions, the name of Lloyd George, the politician who became Prime Minister in late 1916, is pre-eminent, although it is tinged with some ambiguity. It is still the case that Welsh culture celebrates Lloyd George as "the man who won the war", but his reputation is tainted 
by the notion that the entire war was futile and that, for his countrymen, the "victory" was empty.

\section{Broadcasting in Wales}

For the Welsh people, as with other nationalities throughout the developed world, one of the key ways in which they learn about their history is through television programmes. It has been axiomatic for those who study the public's consumption of history that television is key to forming and reinforcing the audience's ideas of historical narratives (de Groot, 2008, p.149-160). Edgerton declared that "television is the principal means by which most people learn about history today" (2001, p.1).

In terms of broadcasting, it has always been the case that the media received by Welsh viewers and listeners is dominated by output produced in England, and more especially London (Barlow, O’Malley \& Mitchell, 2005, p.140). Yet there has always been a degree of autonomy within Welsh broadcasting which allows for the expression of particularly Welsh concerns. Indeed, the great historian John Davies provocatively claimed that modern Wales was "an artefact created by broadcasting", such was the importance of the Welsh broadcasters in "the development of the concept of a national community" (1994, p.ix). In particular the Welsh "national region' of the $\mathrm{BBC}$ has played a central role in Wales' national conversation, and in the creation and reinforcement of Welsh traditions and narratives (Williams, 2003, p.36-7).

One particular reason for having a distinct establishment for the BBC in Wales is the Welsh language. During the first seventy years of the twentieth century, the proportion of the Welsh who were able to speak the national language fell from around $50 \%$ to around $20 \%$, but since then a series of measures have arrested the decline and stabilised the figure. One of the most important of these measures was the establishment of a Welsh television channel (Johnes, 2012, p.311-5). S4C has been broadcasting since 1982, and has evolved from being a service which produced about 22 hours per week in the Welsh language (with the remaining broadcast hours being Channel 4 UK's output) to its current situation of broadcasting a comprehensive service for 120 hours per week solely in Welsh (Barlow, O 'Malley \& Mitchell, 2005, p.145). As well as portraying contemporary Wales, the channel provides "an opportunity for Welsh-speaking Wales to explore its historical roots and represent its past on screen" (Williams, 2008, p.11-12).

Now of course there are multiple channels available for Welsh viewers, but it is only on those stations that are located in Wales that one could expect to have any 'Welsh' dimension to the programming. Up until the early part of this century a decent amount of programmes were produced by ITV in Wales for a Welsh audience, although this has declined following multiple take-overs in the late 1990s and early 2000s (Geraint, 2009, p.56-7).

Thus there exists a duopoly in terms of Welsh programming, with BBC Wales broadcasting a variety of English-language programmes in 'opt-out' slots on BBC1, and S4C broadcasting a Welsh-language service that is as comprehensive as its budget allows. In terms of historical programming, both organisations have a strong trackrecord in commissioning programmes that consider aspects of Welsh history. Some 
larger-scale series have attempted to chart broad swathes of Welsh history, with the most notable recent example being BBC Wales' big budget The Story of Wales in 2012 (Blandford \& McElroy, 2013). Other short series have considered discrete subjects, and there have also been numerous commissions of individual programmes, most often with a specific 'peg' such as an anniversary.

\section{The First World War on British Television and Oral Testimony}

The First World War has been the subject of dozens of hours of television programmes on British television, ever since the landmark series The Great War was broadcast by the BBC in 1964 (Hanna, 2009, p.173-4). This series is noted as a milestone in history programming, and setting the template for a raft of programmes that were to follow, being the first time that archive footage was combined with an authoritative script and interviews with witnesses (Todman, 2005, p.29-35). It was also, as Badsey notes, responsible for establishing the convention "that there are only two perspectives to a major historical event" considered by television history programmes, "those of the very highest political and military leaders, and those of the lowest, the ordinary people at war" (2002, p.39).

However, whether they give a 'top-down' perspective or a 'bottom-up' view, it is overwhelmingly the case that these programmes, like the British popular memory of the War, focus primarily on the trenches of the Western Front. There is also a very strong tendency for British programmes to concentrate only on British fighting, suffering and losses (Hanna, 2009, p.167).

As Hanna has argued, "in contemporary Britain, the act of producing and watching television documentaries about [the First World War] is a remembrance ritual in its own right" (2007, p.108). The programmes are themselves memorials, with the intention of ensuring that the suffering and sacrifices are not forgotten. In this mission one of the producers' most potent tools has been the testimony of the veterans themselves. This was true from the production of The Great War in the early 1960s through to the demise of the last survivor of the trenches (Todman, 2007, p.187). Writing in 2003, when only a handful of British veterans were still alive to tell their stories (and thus each one became the focus of much media attention), a historian and a television producer bemoaned the fact that "First World War documentaries have become the preserve of the veteran. Centenarians are filmed, recording their memories, often for little better reason than the fact that they are centenarians: they have survived" (Strachan \& Lewis, 2003, p. 21).

\section{Oral Testimony in Welsh documentaries about the war}

Programmes produced in Wales about the First World War (whether in Welsh or in English) adhered to this pattern of privileging the memories and viewpoints of the veterans. At the same time as the $\mathrm{BBC}$ was transmitting the series The Great War, ITV in Wales broadcast two programmes Cymru a'r Rhyfel Mawr (Wales and the Great War), which were driven by interviews with eyewitnesses to the events of 1914-1918, albeit with a narrow range of interviewees (Matthews, 2012, p.139). At the time of the sixtieth anniversary of the Somme campaign in 1976, when the BBC broadcast Battle of the Somme, which prioritised the voices of the men who fought 
there (Hanna, 2009, p.22), ITV Wales produced an English language documentary, Scars, in which three Welsh veterans returned to the Western Front.

An opportunity came for Welsh broadcasters to present a particularly Welsh story from the war with the unveiling of the memorial to the $38^{\text {th }}$ (Welsh) Division at Mametz Wood in August 1987. Three documentary programmes were produced to mark the occasion: two in English (on BBC Wales and ITV Wales) and one in Welsh (on S4C). All three programmes depended heavily upon the memories of the veterans to tell the story, and they were inevitably imbued with a sense of pathos as the old men described their suffering 71 years previously. The Welsh-language programme (entitled simply Mametz) provides an example of how programme-makers could use the bilingual nature of the audience to heighten the emotional response. The veterans naturally tell their stories in Welsh, but they switch to English as they recall orders they were given or, in one particularly poignant case, to remember a song that was sung on their way to France. As William John Jones sings in a frail voice "Homeland, homeland, when shall I see you again?", the viewers are hit by the emotional force of the sentiment, which raises further questions: for whom and over what were these Welshmen fighting?

Thus for Welsh programme-makers, as was the general case in Britain, the veterans were placed centre-stage in these programmes and their memories were taken as undeniable facts. Indeed, John Davies introduced the hundred year-old veteran Griffith Williams in the 1988 programme $Y$ Rhwyg with the words "mae'n cofio pob dim" ("he remembers every detail").

As the number of witnesses diminished in the 1990s, programme-makers were anxious that "the last representatives of the First World War generation should not be allowed to slip away without first recording their wartime memories for the nation" (Hanna, 2009, p.25). One exemplar of this is the BBC Wales programme Shadows on the Western Front, filmed in 1993, which recorded the stories of nine Welsh veterans, ranging in age from 94 to 107 . This programme consists almost entirely of just the veterans' own words: there is no voice-over and only a very few questions from an off-camera interviewer. The result is an overwhelmingly powerful emotional experience, as the men recite their tales of horror on the Western Front. Harry Hillman describes waking up with a rat gnawing at his ears, and the experience of getting a lungful of poison gas and seeing his comrades in unbearable pain begging to be shot. Hillman and Fred Wall recount stories of killing German soldiers who had surrendered. George Richards recalls his first battle, and seeing a Welsh and a German soldier locked together in death, having bayonetted each other in the same instant. Bob Owen's stories include details of how four of his comrades were killed in action two days after crossing the channel, how his friend died with a bellyful of machine gun bullets and how 28 of his unit were killed in an instant by a direct hit from a shell.

However, despite the emotional strength of this litany of suffering, there is no attempt to put any of it into context. No reasons are given for why the men were fighting: according to Harry Hillman "we wanted to fight the Germans - that was the main thing, to get at the Germans - I don't know why". Thus the only conclusion available to viewers is that the slaughter was wasteful and meaningless. 
Similarly, Welsh-language programmes focussed on the individual stories of the few remaining witnesses. Both Bob Owen and Griffith Williams, who featured in Shadows on the Western Front, were interviewed on numerous occasions for programmes on S4C. Williams was first interviewed on the occasion of his hundredth birthday: he lived for another eight years and contributed interviews to the programmes Hel Straeon, Y Rhwyg and Canrif y Werin. However, detailed analysis of the content of his interviews shows that many of his recollections are not factually accurate, but rather represent the trope of pointless suffering and violence that are prevalent in the popular cultural understandings of the First World War (Matthews, 2012, 2016).

By the early years of this century, when the number of surviving British veterans was down to single figures, some became regular contributors to programmes. Most notable of these was Harry Patch, who (with some reluctance) became the representative of all the British 'Tommies' when he was the last surviving veteran of the trenches (Patch with van Emden, 2007). Thus there had developed what AudoinRouzeau and Becker have called the "tyranny of the witness", whereby the mood was that the men who had been there in the fighting of 1914-18 had the "exclusive right to talk about the experience" (2002, p.38-9). How, then, would the situation evolve once there were no more witnesses to interview?

One response, to be considered briefly, has been for the programme-makers to recycle the existing interviews. In British terms, the key example is The Great War Interviews: extended clips of the interviews done with veterans for the 1964 series. As well as being broadcast as a conventional programme (I Was There: The Great War Interviews), these are now a valuable resource available via the $\mathrm{BBC}$ website. Similarly, BBC Wales re-packaged a variety of interviews from over the decades into two half hour programmes, Welsh Memories of World War I (first broadcast September 2014) and ITV Wales have re-worked their archive interviews regarding the Western Front into two half hour programmes, Dragons on the Somme (first broadcast July 2016). S4C simply repeated the 1987 programme Mametz at the time of the battle's centenary.

However, another response from the programme-makers has been to explore different ways of viewing the conflict now that they are liberated from their reliance on a few voices. This article will next examine three series broadcast on S4C during the period of the ninetieth anniversary of the conflict which demonstrated how programmemakers could move on once there were no more witnesses to interview.

\section{Welsh-language programmes broadcast during the ninetieth anniversary period}

Even though the number of hours produced in the Welsh language is limited (currently around 37 hours of new programming per week), the First World War is a subject that has continued to receive a significant amount of attention on S4C. A number of series and single documentaries have been broadcast, with the transmission most often co-inciding with an anniversary.

Table 1: Original programmes about the First World War broadcast on S4C, 2004-2014 


\begin{tabular}{|c|c|c|}
\hline Title & Translation & First broadcast \\
\hline \multicolumn{2}{|c|}{\begin{tabular}{l|l} 
Series broadcast during the ninetieth & \\
anniversary of the First World War &
\end{tabular}} & \\
\hline Cerdded y Llinell & Walking the Line & 24 Oct. 2004 \\
\hline Galipoli & Gallipoli & 19 April 2005 \\
\hline Lleisiau'r Rhyfel Mawr & The Voices of the Great War & 4 Nov. 2008 \\
\hline \multicolumn{2}{|c|}{$\begin{array}{l}\text { Programmes broadcast around the centenary } \\
\text { of the start of the First World War }\end{array}$} & \\
\hline Dyddiaduron y Rhyfel Mawr & Diaries of the Great War & 8 June 2014 \\
\hline Gwaed Gwirion & Wild Blood [title of novel] & 28 July 2014 \\
\hline Dyddiadur Ellis: Y Claf Cyntaf & Ellis' Diary: the first casualty & 31 July 2014 \\
\hline Pwy Sy'n Gwisgo'r Trowsus? & Who wears the trousers? & 27 Sept. 2014 \\
\hline $\begin{array}{l}\text { Gwrthwynebwyr y Rhyfel } \\
\text { Mawr }\end{array}$ & Objectors to the First World War & 28 Sept. 2014 \\
\hline Tir Neb & No-man's land & 28 Sept. 2014 \\
\hline Y Pymtheg Olaf & The final fifteen & 9 Nov. 2014 \\
\hline
\end{tabular}

Cerdded $y$ Llinell is a six-part series which focusses explicitly on the Western Front, first broadcast in the run-up to Remembrance Sunday, ninety years after the start of the war. Two well-known presenters, the naturalist Iolo Williams and the jovial academic Hywel Teifi Edwards trace the line of the trenches from Ypres to Verdun, recounting stories of the conflict from not just the Welsh viewpoint, but also including details of the French, British and other Allied nations, and of the Germans. Each programme includes a variety of first-person testimony from the soldiers who had witnessed the action, with their accounts relayed by the presenters themselves (mostly in pieces-to-camera [PTCs]). A limited amount of genuine archive footage is included, together with material staged by re-enactors. However, the dynamic that drives the narrative forward is the conversation between the two presenters, as they try to reconcile the stories of destruction and massacre with the peaceful calm that they witness in the countryside of Flanders and France.

It has been suggested that presenter-led history programmes can either fall into the category of having presenters who are omniscient experts who tell the viewer what happened, or of having presenters who are keen to discover "the truth" and who lead the viewers on a "quest" (Bell \& Gray, 2007, p.128-130). There are potential pitfalls with both approaches: the first runs the risk of ignoring the complexity of events by giving an over-simplified narrative, while the second approach might weaken the authority of the presenter to give a definitive view of what happened. However, having two powerful presenters working together, Cerdded y Llinell succeeds in conveying a lot of information in a coherent narrative without pretending that there are answers to all of the questions. Indeed each of the programmes finishes with a conversation between the two as they attempt to make sense of the story as best as they can. Edwards, an expert in Welsh literature, usually finds words in poetry to express his feelings while Williams seeks metaphors from the natural world. 
The first half of the fourth programme tells the story of Mametz Wood, which is told as a story of Welsh endeavour against the odds. The end of the sequence is particularly powerful, as the presenters stand in the shadow of the battlefield's red dragon memorial, trying to put their emotions into words. The part finishes with Edwards reciting the most famous, and most poignant, lines by Hedd Wyn, the poet whose loss has for decades epitomised for a Welsh audience the talent that was destroyed by the war.

The fact that the series is ordered by geography rather than chronology can lead to the potential for confusion in the narrative. The first programme, for example, includes details of the fighting around Ypres in 1914, 1915, 1917 and in the final months of the war. However, a consequence of this geographical approach is that the final programme moves resolutely away from a Welsh/British-centred approach, focusing as it does on the area around Verdun. Thus the presenters have the space to take a step back from the usual concentration on British soldiers' suffering, and to consider the war as a European, and a global tragedy.

One commission that sprang from the series Cerdded y Llinell was Galipoli, the Welsh version of the international co-production Revealing Gallipoli. This was initially an Australian-led venture, produced by Melbourne-based December Films, which brought in expertise and finance from New Zealand, Ireland, Wales and, significantly, Turkey (Stanley, 2012). The production company made thirteen different versions of the programme in three languages. The version for $\mathrm{S} 4 \mathrm{C}$ was broadcast as two hour-long programmes on the ninetieth anniversary of the start of the campaign, and again featured Hywel Teifi Edwards and Iolo Williams as copresenters.

The principal drivers of the narrative are the on-screen presences of Williams and Edwards. We see them in a variety of locations, in London and Istanbul as well as at the battle-sites in Gallipoli itself. Most often they are geographically apart, so that they can relate different parts of the action, though they are seen together in the programmes' opening PTCs and in certain locations such as Y Beach (where the South Wales Borderers landed on the first day of the campaign). Both presenters give details of the background to the campaign and focus upon the activities of individual participants. One noteworthy element of this production is the substantial presence of the Turkish presenter, Savaş Karakaş, who describes the actions and feelings of those on the Turkish side (speaking in Turkish, with sub-titles in Welsh). Indeed, of the 55 PTCs in the first programme, two are double-headers with both Edwards and Williams; Edwards delivers 19 by himself; Williams 21 and Karakaş ten. In the second programme, the first and final PTCs are delivered by Karakaş.

In the telling of such an enormous campaign (which eventually involved over 800000 men), the programme focuses upon the experiences of a few individuals. Naturally, given the audience, three of the combatants given attention are Welsh: the collier Tom Rees from South Wales and the quarrymen from North Wales, brothers Richard and Robert Williams. The impact of the campaign upon Welsh communities is highlighted by the close-up towards the end of the second programme of the war memorial in Penmaenmawr, which lists the Williams brothers. 
However, the narrative strives hard not to dwell upon solely Welsh involvement, and focusses upon a number of individual Australians, Englishmen, Irishmen and Turks. The story of one local youth, Adil Shahin, a sixteen-year old farm boy conscripted into the Ottoman army, is woven into the fabric of the programmes. His words describe how for him it was a fight to defend his home: these sentiments are given to the audience throughout the programmes as a voice-over in Welsh translation. Then, at the end of the second programme, there comes an excerpt from a 1985 interview with Shahin, where he himself (in Turkish, with Welsh sub-titles) gives a message of reconciliation.

Thus both the series fronted by Edwards and Williams during the ninetieth anniversary period moved on from giving a narrow history focussing on the combat experiences of one particular cohort. Naturally there was a focus upon particular Welsh individuals and communities, but this was understood to be part of a wider picture. The numerous impacts of the campaigns were considered across a variety of different contexts in a range of countries and the programmes reflected upon their legacies over a long time-span.

The next series broadcast about the war was shown ninety years after the Armistice. Lleisiau'r Rhyfel Mawr chose a chronological re-telling of the story of the war, with each of the four episodes covering a different year of the conflict. This series was built upon a solid base of primary research, sharing a wealth of first-person testimony principally from contemporary letters written by soldiers to their families or to local newspapers (ap Glyn, 2008). Once again, the viewpoint is firmly 'bottom up', sharing the perspective of those who were serving on the front line rather than those higher up the army's chain of command.

The presenter of the series is Ifor ap Glyn, a renowned poet and television producer (who has since branched out into further appearances in front of the camera).

However, his presentation style is deliberately low-key, the better to avoid taking attention away from the programmes' key component, the contemporary eyewitness testimony. A high number of individual soldiers are quoted, from a range of Welsh communities. In an eloquent allusion in the first programme, ap Glyn compares this collection of letters to one of the earliest extant examples of Welsh, the war poem $Y$ Gododdin, which tells of a destructive battle in the sixth Century. The reference is telling as not only does it set the scene for an all-out war, but also it firmly locates this conflict within Welsh culture.

In terms of the presentation of the material the influence of Ken Burns' landmark series on The Civil War was clear. Indeed, ap Glyn had been the producer/director of a Welsh-language series on the American Civil War which had explicitly cited Burns' series as an inspiration (Hunter \& ap Glyn, 2004). Extracts from the soldiers' letters are read by actors with the appropriate regional accents, with the quotations being closed (as in Burns' series) with the author's name and service details. The authenticity of the extracts is demonstrated to the audience by the use of close-ups of particular phrases in the original letters.

As well as the campaigns on the Western Front there was substantial consideration given to the experiences of soldiers in the campaigns in Gallipoli and Egypt / Palestine. The presenter is seen on location in numerous evocative battlefield sites 
and, in every programme, walking through the extensive ranks of headstones in war cemeteries. On several occasions he stops by the grave of a soldier referred to in the letters.

The series also makes good use of the bilingual nature of the audience to highlight points about the soldiers' experiences. For example in episode three, in an extract from Francis Buller Thomas' writings, the narration switches from Welsh to English when the soldier-author is shouted at by an officer.

It is clear that the two series Cerdded y Llinell and Lleisiau'r Rhyfel Mawr present a narrative of the First World War that is firmly anchored in Welsh culture and guided by Welsh pre-occupations. Both, for example, dwell upon the tragic story of Hedd Wyn and go into minute detail regarding the Battle of Mametz Wood. Yet both series also attempt to encapsulate the universal tragedy of the war. This point is explicitly and eloquently made by Edwards in Cerdded y Llinell as the two presenters contemplate the sight of Hedd Wyn's grave on a sunny Flanders afternoon. He declares that the artistic reaction to the loss of Hedd Wyn had made him into a "kind of universal figure": the archetype of a creative young soldier who was killed alongside thousands of others. Similarly, the final programme of Lleisiau'r Rhyfel Mawr includes a poignant sequence in which a Welsh soldier tells how he befriended some young German prisoners-of-war, and wonders whether they are any different to him in their humanity. Both these series and Galipoli make it clear to the Welsh audience that loss and suffering in the war was not one-sided.

\section{Welsh-language programmes broadcast at the centenary}

The next round of documentaries commissioned by S4C to focus on the First World War were broadcast to mark the centenary of the start of the conflict. There was an appetite in the lead-up to August 2014 to revisit the seminal conflict of the twentieth century and to try to understand its consequences. The UK broadcasters sought to capitalise, with the $\mathrm{BBC}$ being particularly prolific in commissioning programmes.

Some months before the actual centenary, the ball began to roll with a four-part series on Britain's Great War (broadcast January / February 2014) and two high profile programmes (broadcast late February 2014) that examined the geo-political picture that led to the outbreak of the war (The Necessary War and The Pity of War). As well as these attempts to explain the political and social background to the global war, a number of programmes broadcast by the BBC under the umbrella 'World War One at Home' have examined a variety of different social and cultural responses to the changed circumstances of wartime. Naturally the experiences and demands of the soldiers on the fighting fronts cast their shadow over these programmes, but they are still able to explore the multiple narratives of wartime away from the mud of France and Flanders. These programmes reject any 'top-down' retelling of the story of the war, and grapple with the variety of responses that were seen between 1914 and 1918 .

Notable programmes were commissioned by other UK broadcasters, such as the four part series The Great War: The People's Story, broadcast by ITV in August 2014 and WW1's Forgotten Heroes broadcast by Channel 4 in November 2014. These

documentaries focussed on the war experiences of specific individuals, using a wealth of contemporary evidence. The ITV series dramatized the letters written and received 
by a dozen main characters (male and female; servicemen and civilian), whereas the Channel 4 programme was a presenter-led investigation into the experiences of those who were disfigured by the war.

S4C commissioned a number of Welsh-language programmes for the centenary period (as well as repeating the series Lleisiau'r Rhyfel Mawr). In contrast to some of the major BBC commissions, none of the S4C programmes attempted to deal with the global geo-politics, nor to detail the military campaigns. Instead, in a similar way to the programmes cited by ITV, Channel 4 and the BBC's 'World War One at Home' offerings, S4C's programmes took more of a micro-historical approach, focussing on individual stories and on the social and cultural effects of the war.

Thus in the week before the centenary of the outbreak of war there was an examination of the most highly-regarded Welsh-language novel about soldiering in the First World War (Gwaed Gwirion), and a programme on a soldier who was badly disfigured in the Battle of Mametz Wood (Dyddiadur Ellis). A few weeks later two programmes were broadcast which looked at the assault of the war upon the fabric of Welsh society. Pwy sy'n gwisgo'r trowsus? explored the radical changes to women's lives, as they gained new opportunities and (at least for the duration of the war) felt that their contribution was noted and valued. On the other hand, Gwrthwynebwyr $y$ Rhyfel Mawr dealt with the stories of those who resisted the call to arms, and refused to be conscripted into the armed forces on political or religious grounds.

Welsh versions were also produced of two international co-productions which focussed on the stories of numerous combatants and civilians from all over Europe. Dyddiaduron y Rhyfel Mawr was broadcast as an eight part series from June 2014, and in late September 2014 the 90 minute programme Tir Neb was screened. Then in November Y Pymtheg Olaf told the story of the Welsh international rugby players who were caught up in the conflict - of the fifteen that represented Wales in the final peacetime match in 1914, nine saw active service in the war and one was killed.

Thus a variety of topics were covered in some detail by a range of programmes, representing a substantial commitment of budget and screen-time for a small channel such as S4C. In contrast to the typical programmes of previous decades, there was only a limited focus on the fighting on the Western Front and much more attention was given to attitudes and activities on the Home Front. The principal focus was upon the conflict's impact upon families and communities back in Wales, and how Welsh society and culture in general was affected by the war.

None of the programmes contained interviews with veterans, although the programme Gwrthwynebwyr y Rhyfel Mawr did include excerpts from archive television interviews with two who had been imprisoned for being conscientious objectors. All of the programmes present primary source evidence written during the war by those involved: the principal source of information in Dyddiadur Ellis is the journal of Ellis Williams, written as he was recovering in hospital from severe facial wounds. This programme, like most of the others considered here, features relatives of the individuals whose stories are told. Williams' nephews and nieces add contextual information to the material in the diary, and relate how they in the present day understand and feel about the events of a century ago. There is no presenter in Dyddiadur Ellis, but the interviewees speak directly at the camera. 
There is no on-screen presenter either in Gwrthwynebwyr y Rhyfel Mawr, Pwy sy'n gwisgo'r trowsus? nor the two international co-productions. Dyddiaduron y Rhyfel Mawr was the Welsh version of the international co-production, 14 Tagebücher des Ersten Weltkriegs (broadcast by the BBC as Great War Diaries: Peter, 2014). Over eight episodes, this tells the story of fourteen principal individuals during the war years, and a number of minor characters. As well as hearing voices from Britain, Germany, France, Italy, Austria and Russia there are contributions in Magyar and in Welsh. Tir Neb was the Welsh version of the film Im Krieg, produced by Parallax and LOOKS Film. This includes extracts from contemporary writings in a variety of languages: German, French and English as well as Welsh. We hear the beginnings of the contributions in other languages before a Welsh voice-over takes over. The effect of both these productions is to impress upon the viewer the complex multi-national nature of the global conflict while simultaneously insisting upon the Welsh language's presence as part of that mix.

Gwrthwynebwyr y Rhyfel Mawr uses a female voice-over to introduce the stories of four conscientious objectors. The programme uses interviews with relatives and academics as well as the words of the men themselves (either from archive interviews or from their contemporary writings). Of course, given that the four saw no military action themselves, the focus of the programme is very much on the social and cultural implications of the war rather than on the fighting in the trenches. In a similar fashion, Pwy sy'n gwisgo'r trowsus? tells the stories of a number of Welsh women during the war years using primary source material from the period and interviews with relatives. The individuals featured all saw major transformations in their lives, as they took on new roles as nurses or munitions workers, or doing work that had previously been reserved for men.

The two programmes with the strongest presenter-presence are Gwaed Gwirion, presented by Professor Gerwyn Wiliams, and Y Pymtheg Olaf, presented by Dafydd Jones. Wiliams presents a powerful case for why the novel Gwaed Gwirion about a soldier's experiences in the war should be regarded as a Welsh literary classic, despite the evidence he discovered that much of it was plagiarised from an American novel. Jones, a popular retired rugby player, tries to understand the impact of the war upon Wales through the lens of sport by finding out the fate of a number of rugby internationals, as well as finding out about his own family connections to the war.

The presenters in both these programmes travelled to the battlefields of France, yet in the two programmes there is as much attention paid to the cultural impact of the war upon Wales as there is to the details of the fighting. Gwaed Gwirion considers how the memory of the war remained alive within Welsh communities, showing how the stories told to one young man became so engrained in his imagination that when he became an author he succeeded in giving a convincing first-person narrative of the fighting.

In visual terms, there is a great deal of dramatic reconstruction on offer in Dyddiadur Ellis, Y Pymtheg Olaf and in the co-production Dyddiaduron y Rhyfel Mawr. All of the programmes make use of contemporary newsreels and photographs: the one with the most creative use of these visuals is Tir Neb, where the producers were able to capitalise upon the bigger budget available to this international co-production. 
However, all of these programmes strive to use relevant photographs from the period, often ones held by families that have not been previously publicly available. As well as giving the producers the opportunity to boast of 'previously unseen material', this heightens the sense of empathy that the viewer feels for those whose story is being told.

Thus there are a number of interesting patterns to be discerned from studying the Welsh-language programmes about the First World War that have been produced since the ninetieth anniversary of the start of the war. There are distinctly Welsh narratives in the history that is told by these programmes, yet as a whole they inescapably work within a wider 'British' interpretative framework. McElroy has suggested that viewers of S4C are bicultural, in the sense that "they are used to switching between the cultural codes of different national broadcasters" (2008, p.242). Skilful producers have been able to use this fact to their advantage in First World War documentaries. For example, many of the programmes considered have used the familiar trope of the suffering of the infantry on the Western Front, the 'lions led by donkeys', and then highlighted the fact that the Welsh 'lions' were led by upper-class English 'donkeys'.

In general it is clear that there has been a shift from a military history of the war towards a cultural history. As well as considering events on the battlefield, developments in practices and attitudes in society at large are part of the story. Various other commissions for UK broadcasters have also followed the same path away from telling the story of battalions and divisions, and instead focussing upon the experiences of the individuals whose lives were changed by the conflict. This also implies a move away from a British-centred approach to try to encompass the universality of the conflict. Perhaps this shift is related to the disappearance of veterans' interviews from the screen following the passing of the final eyewitnesses. No longer does the story have to be told from just the viewpoint of those who were in the trenches.

Dillon argues that one of the principal reasons that academic history has an uneasy relationship with television history is the latter's over-reliance on eyewitness testimony, taking these interviews unquestioningly as a genuine narrative of "what really happened" (2010, p.27). The historians had plenty of grounds for this criticism of First World War documentaries in the years when interviews with veterans dominated the narrative. However, there has been a clear shift since the turn of the millennium towards including a broader spectrum of viewpoints, and this is seen clearly in the Welsh-language programmes under consideration. The experiences of the soldiers are still recognised as pivotal, and the programmes remain very much a memorial to those who died or were scarred by the conflict. Nevertheless, in these newer programmes the trenches of the front line are understood as not the only sites of suffering and loss. 

. Audoin-Rouzeau, S. \& Becker, A. (2002). 14-18: Understanding the Great War. Hill and Wang. New York.

. Badsey, S. (2002). The Great War Since The Great War. In: Historical Journal of Film, Radio and Television, 22 (1), p.37-45.

. Barlow, D. M., O’Malley, T., Mitchell, P. (2005). The Media in Wales: Voices of a Small Nation. University of Wales Press. Cardiff.

. Bell, E. \& Gray, A. (2007). History on television: Charisma, narrative and knowledge. In: European Journal of Cultural Studies, 10 (1), p.113-133.

. Blandford, S. \& McElroy, R. (2013). Memory, Television and the Making of the BBC's 'The Story Of Wales'. In: VIEW Journal of European Television History and Culture. http://viewjournal.org/index.php/view/article/view/jethc038 accessed 18.6.2016.

. Bond, B. (1991). Editor's Introduction. In: Bond, B. (ed.) The First World War and British Military History. Clarendon Press. Oxford, p.1-12.

. Davies, J. (1994). Broadcasting and the BBC in Wales. University of Wales Press. Cardiff.

. Dillon, R. (2010). History on British Television: Constructing Nation, Nationality and Collective Memory. University of Manchester Press. Manchester

. Edgerton, G.R. (2001). Introduction: Television as Historian - A Different Kind of History Altogether. In: Edgerton, G. R. \& Rollins, P. C. (Eds.) Television histories : shaping collective memory in the media age. University Press of Kentucky. Lexington

. Hanna, E. (2007). A small screen alternative to stone and bronze: The Great War series and British Television. In: European Journal of Cultural Studies, 10/ 89, p.89111.

. Hanna, E. (2009). The Great War on the Small Screen: Representing the First World War in Contemporary Britain. Edinburgh University Press. Edinburgh.

. Geraint, J. (2009). Convergent Realities. In: Davies, G. T. (ed.) English is a Welsh Language: Television's Crisis in Wales. Institute of Welsh Affairs. Cardiff, p.54-60.

. ap Glyn, I. (2008). Lleisiau'r Rhyfel Mawr. Gwasg Carreg Gwalch. Llanrwst.

. de Groot, J. (2008). Consuming History: Historians and Heritage in Contemporary Popular Culture. Abingdon; New York. Routledge.

. Hunter, Jerry \& ap Glyn, Ifor (2004). Dehongli Rhyfel Cartref America: Llun, Llên a Llwch. In: Cyfrwng (1), p.62-76. 
. Johnes, M. (2012). Wales since 1939. Manchester. Manchester University Press.

. Matthews, G. (2012). "Sŵn yr ymladd ar ein clyw”: Cyflwyno'r Rhyfel Mawr yn y Gymraeg. In: Gwerddon, 10/11 pp.132-157

. Matthews, G. (2016). Rhwng Ffaith a Ffuglen: Atgofion Cyn-filwyr Cymraeg mewn Cyfweliadau Ddegawdau wedi Diwedd y Rhyfel. In: Matthews, G. (Ed.), Creithiau: Dylanwad y Rhyfel Mawr ar Gymdeithas a Diwylliant yng Nghymru. University of Wales Press. Cardiff.

. McElroy, R. (2008). Indigenous minority-language media: S4C, cultural identity and the Welsh-language televisual community. In: Wilson, P. \& Stewart, M. (eds.) Global Indigenous Media. Durham, NC. Duke University Press. p.232-249.

. Morris, R. C. (24.8.2012). Celebrating a Gifted Welsh Poet. In: New York Times. Accessed via http://www.nytimes.com/2012/08/25/arts/25iht-conway25.html on 5.7.2016.

. Patch, H. with van Emden. R. (2007). The last fighting Tommy : the life of Harry Patch, the oldest surviving veteran of the trenches. Bloomsbury. London.

. Peter, J. (2014). Great War Diaries: Turning diaries into compelling drama. Accessed via http://www.bbc.co.uk/blogs/tv/entries/89f6b75e-76e4-3d84-974d2426bfd3a562 on 8.7.2016.

. Stanley, P. (2012). Revealing Revealing Gallipoli. In: Bennett, J. E. \& Beirne, R. (eds.), Making Film and Television Histories: Australia and New Zealand. I.B. Tauris. London, p.143-8.

. Strachan, H. \& Lewis, J. (2003). Filming the First World War. In: History Today, 53 (10), p.20-2

. Todman, D. (2005). The Great War: Myth and Memory. Bloomsbury. London.

. Williams, K. (2003). Constructing the National: Television and Welsh Identity. In: Scriven, M. \& Bell, E. (eds.) Group Identities on French and British Television. Berghahn Books. London, p.34-40.

. Williams, K. (2008). Flattened visions from timeless machines: History in the mass media. In: Nicholas, S., O'Malley, T. \& Williams, K. (eds.) Reconstructing the Past: History in the Mass Media 1890-2005. Routledge. Abingdon. 
Since 2011 Dr Gethin Matthews has been a lecturer in the Department of History at Swansea University, specializing in the First World War, the history of the Welsh overseas and representations of history in the media. In 2016 the University of Wales published his edited volume Creithiau, the first academic history book in Welsh about the First World War for twenty years. He is currently running a project on memorials to the First World War in Wales, funded by the Living Legacies 1914-18 Engagement Centre. Prior to becoming an academic he had a career in the Welsh television industry. 